\title{
Identification of the Roll Response for the Cessna Citation X Business Aircraft Engine
}

\author{
Ruxandra Mihaela Botez ${ }^{1 *}$, Julian Anthony ${ }^{1}$ and Clement Hamel ${ }^{1}$ \\ ${ }^{1}$ ETS, University of Quebec, Montreal, Que., Canada, H3C1K3 \\ *e-mail address: $\underline{\text { ruxandra.botez@etsmtl.ca }}$
}

\begin{abstract}
The Research Aircraft Flight Simulator was designed and manufactured by CAE Inc., which is a very well known internationally Aerospace Company in Aircraft Modeling and Simulation Technologies. This simulator was designed following specific requirements of the Laboratory of Applied Research in Active Controls, Avionics and AeroServoElasticity LARCASE team at ETS in Montreal with the aim to be used for research purposes. The authors are the members of the team. This simulator is equipped with a Flight Dynamics Level D open source code, thus it will be used as a Flight Certified Bench Test with the idea to validate Flight Dynamics Models new codes and methodologies. The Cessna Citation $\mathrm{X}$ is the fastest today business aircraft available on the market. The authors used this simulator in order to establish a new methodology for the identification of the roll response.
\end{abstract}

\section{Introduction}

The Cessna Citation $\mathrm{X}$ business aircraft flight dynamics model was identified and validated as explained in $[1,2]$. Various optimal control methodologies have been studied for the Cessna Citation $\mathrm{X}$ in [3, 4, 5]. The engine of the Cessna Citation $X$ was identified in $[6,7]$.

The main objective of this research was to determine the variation of main parameters of the Cessna Citation X, with initial angle of attack and Mach numbers during the Roll response mode. These parameters include the aerodynamic derivatives such as the rolling moment due to roll rate $\boldsymbol{L}_{\boldsymbol{p}}$ and $l_{p}$, and the $\boldsymbol{L}_{\boldsymbol{\delta}_{\boldsymbol{a}}}$ (Rolling moment due to aileron deflection $\boldsymbol{L}_{\boldsymbol{\delta}_{\boldsymbol{a}}}$ and $\boldsymbol{l}_{\boldsymbol{\delta}_{\boldsymbol{a}}}$.

\section{Methodology}

The Roll response, as mentioned in the literature, is a lateral mode of an aircraft. During the roll of the aircraft, is known that the difference in lift caused by the wings creates a moment that tends to being the airplane back to equilibrium. The roll rate $p$ and roll angle $\varphi$ may be modeled for the deflections of the aileron angle $\boldsymbol{\delta}_{\boldsymbol{a}}$.
Both approaches were used in this research, the time domain or state space representation, and the frequency domain or the transfer function modeling.

The Roll response is a lateral mode of an aircraft. Here, the aircraft rolls, where the wing that descends has an increase angle of attack while the other behaves oppositely. The difference in lift caused by the wings creates a moment that tends to being the plane back to equilibrium. The roll rate $(p)$ and roll angle $(\varphi)$ were modeled for a deflection in aileron angle $\left(\boldsymbol{\delta}_{\boldsymbol{a}}\right)$.

The time domain and frequency domain approaches were both used in this project. The time domain approach used a steady state representation to model the roll response mode whereas the frequency domain approach used transfer functions.

It has been chosen to perform a set of roll response flight tests using the JJ10 protocol. The aircraft was made to roll in one direction around 10 seconds, hold its position for 5 seconds, then roll to the other end in 20 seconds, then hold for 5 seconds before returning back to its initial position in 10 seconds. During these tests, only one 
rudder was considered. The following diagram illustrates this change, where rudder 1 is the lighter colored line.

In order to use the Time Domain approach, the flighttest.ident.ls function was used to estimate the derivatives of aerodynamic coefficients using the Least Squares method. Hence, given the independent and dependent variables, the derivatives with respect to the independent variables were calculated.

The following combination gave the best results using the time domain approach. A combination of trial and error based also on literature findings was done in order to find the following equations where the coefficients $L_{p}, L_{\square_{a}} N_{p}$ and $N_{\square_{a}}$ are the coefficients to be determined:

$$
\begin{aligned}
& L=L_{0}+L_{p} p+L_{\delta a} \delta_{a}+L_{v} v+L_{r} r+L_{\delta r} \delta_{r} \\
& N=N_{0}+N_{p} p+N_{\delta a} \delta_{a}+N_{v} v+N_{r} r+N_{\delta r} \delta_{r}
\end{aligned}
$$

The tfest function estimated the continuoustime transfer function in the frequency domain. The coefficients have been estimated based on the input and output data, initial conditions and sampling period. The FAA criterion was taken into account for the Roll response mode value $p$ that would depend on the difference between the model and experimental roll rate $p$.

All the estimated coefficients during validation tests were interpolated using their initial angle of attack and Mach number, and they were further introduced into the state space/transfer function representation to produce the modeled roll rate $p$ and roll angle $\phi$.

\section{Results}

It has been noted that the frequency domain approach gave much better results than the time domain approach. Graphs were traced for the model identification and validation, successful and failed tests for both approaches. Results were obtained for the identification and validation of tests 1 and 2 for the variation of the roll rate $p$ and roll angle $\phi$ with time, where model simulated data were compared with experimental flight test data. As previously mentioned, the FAA criteria for a successful Roll response test was demanding. Recalling, the difference between the modelled and experimental roll rates had to be within $10 \%$ or $2 \% \mathrm{sec}$. In other words, if only all the points in the two graphs obeyed the criteria, the particular test was a success.

Results were obtained using the two different time and frequency domain approaches. A number of 263 identification tests and 10 validation tests were performed.

The flight envelope shown below gives the Gross weight GW and Centre of gravity CG 13 points used to perform the tests. For each point, a number of 21 tests were conducted at different altitudes and CAS, thus 263 points were obtained.

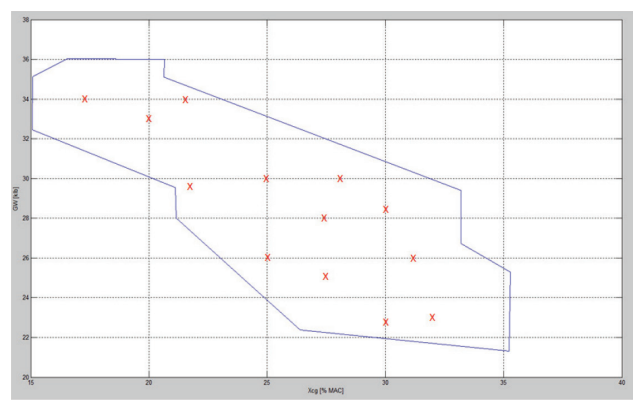

Figure 1. Flight Envelope

These tests were performed at different altitudes and Calibrated Air Speed CAS values for different aircraft weights and center of gravity positions. The successful identification and validation ratios were both much better in the frequency domain than in the time domain. The successful identi-fication ratio was 81.4 in the frequency domain, while its value was 46.1 in the time domain. The successful validation ratio was 40 in the frequency domain, while its value was 60 in the time domain.

The number of tests considered in the Time Approach methodology for which more than $90 \%$ of the points respected the 
FAA criteria was 209 in the time domain and 254 in the frequency domain. Because on the frequency domain approach, 254 out of the 263 tests belonged to the FAA criteria, it meant that this frequency approach better than the time domain approach. The time domain gave also a very good number in this category (209 out of 263), that confirmed that this approach was also an adequate one.

In the following Figures 2 and 3, the envelope was represented with continuous line, the sucessful identification tests were presented with crosses $(+)$, the successful validation tests were represented with circles and the failed validation tests were presented with $\mathrm{x}$.

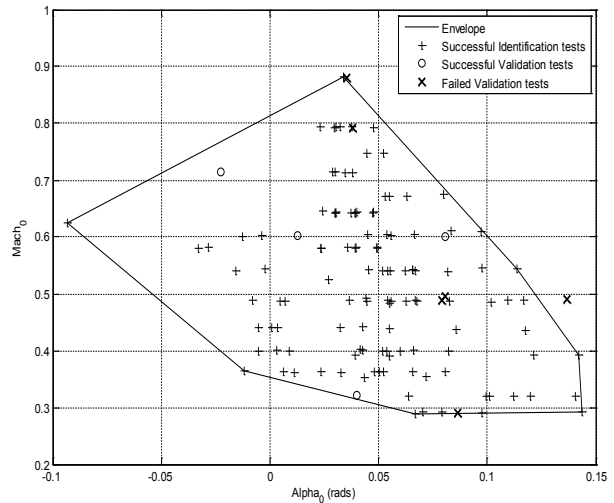

Figure 2. Envelope versus Successful Validation, Successful Identification and Failed Validation Tests (Time Approach)

As shown in Figure 2, there are two points outside the envelope, and for this reason, these points were not validated.

As shown in the next Figure 3, the frequency domain approach had only 4 failed validation tests.

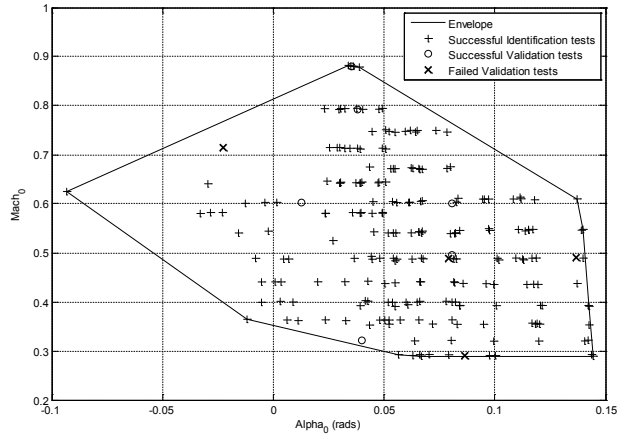

Figure 3. Envelope versus Successful Validation, Successful Identification and Failed Validation Tests (Frequency Approach)

The next Table 1 shows the closeness of the failed validation tests to the successfully validated tests. The $\%$ is giving the number of test points that respect the FAA criteria. Three (3) out of the four (4) tests from the frequency domain approach were above $99 \%$. This means that only few points have not respected the FAA criteria, and therefore failed validation tests were obtained instead successful validation tests.

\begin{tabular}{ccc}
$\begin{array}{c}\text { Experiment } \\
\text { No. }\end{array}$ & $\begin{array}{c}\text { Time } \\
\text { Domain }\end{array}$ & $\begin{array}{c}\text { Frequency } \\
\text { Domain }\end{array}$ \\
\hline 1 & 88.2 & 100 \\
2 & 100 & 100 \\
3 & 93.38 & 98.34 \\
4 & 86.24 & 99.62 \\
5 & 100 & 100 \\
6 & 100 & 99.62 \\
7 & 0 & 99.36 \\
8 & 100 & 100 \\
9 & 96.69 & 100 \\
10 & 0 & 100
\end{tabular}

The identified coefficients for the $\mathrm{Lp}$ and $L_{\delta_{a}}$ are shown in the next Figures 4 and 5: 


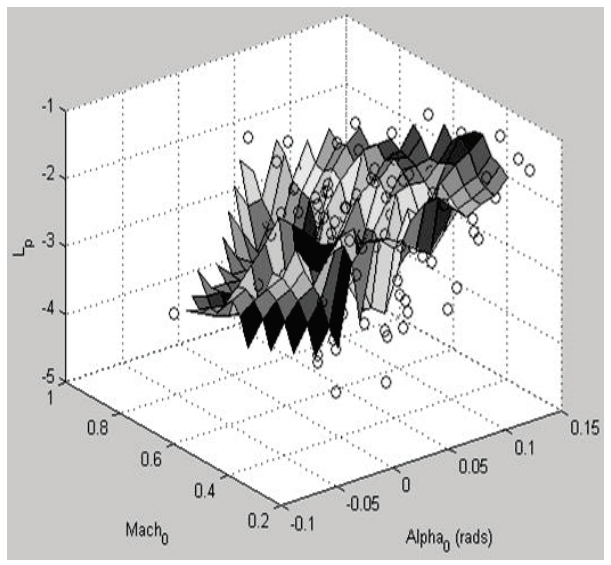

Figure 4. Lp versus Mach number and angle of attack

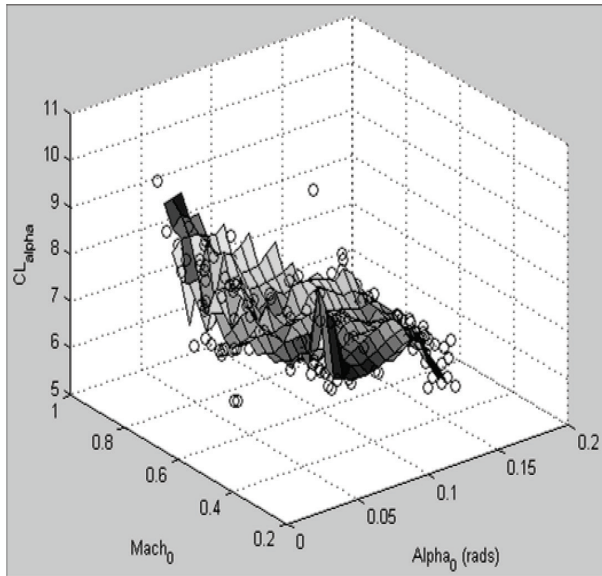

Figure 5. The aerodynamic derivative of lift coefficient $C_{L_{\alpha}}$ with the angle of attack versus

Mach number and angle of attack

$C_{L_{p}}$ is related to $C_{L_{\alpha}}$ by the following relationship;

$C_{L_{p}}=\frac{-4 C_{L_{\alpha}}}{S b^{2}} \int_{0}^{b / 2} c y^{2} d y$

$C_{L_{\alpha}}$ is positive and decreases with angle of attack.

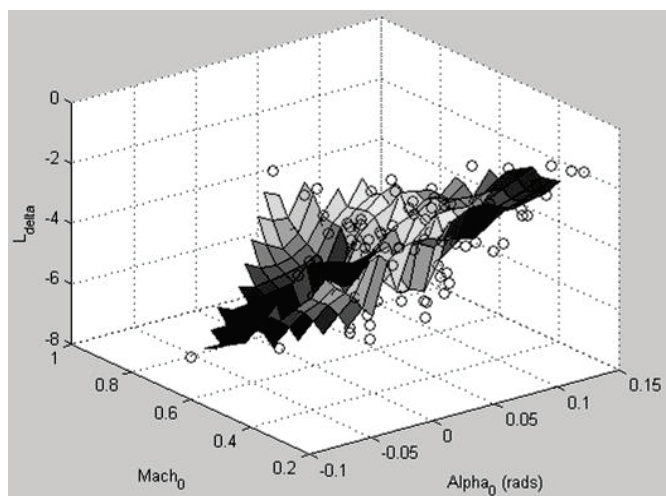

Figure 6. $L_{\delta_{a}}$ versus Mach number and angle of attack

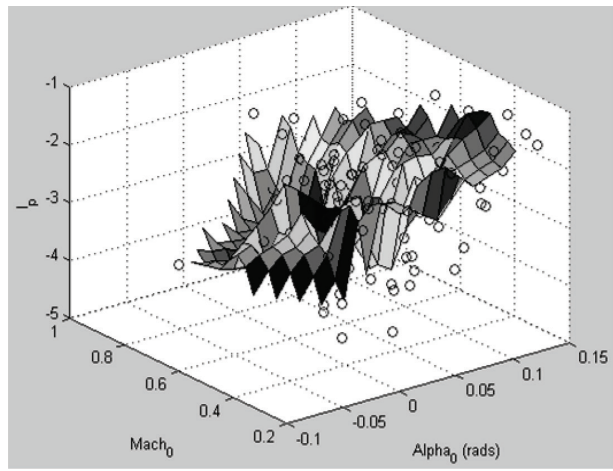

Figure 7. $l_{\delta a}$ versus Mach number and angle of attack

As the angle of attack increases, a decrease in the magnitude of $L_{\delta_{a}}$ can be observed in Figure 6 . The control effectiveness of the ailerons tends to decrease with high angles of attack that could be attributed to this trend.

At high angles of attack, the roll moment created by certain deflection in aileron decreases while there is no relationship between $L_{\delta_{a}}$ and the Mach number. The variation of the aerodynamic coefficients $l p$ and $l_{\delta a}$ with Mach number and angle of attack is shown in Figures 6 and 7.

\section{Conclusion}

The results obtained through the frequency domain approach were better than the 
results obtained using the time domain approach.

In the frequency domain method, it is possible to separate modes while modeling. In this particular case, the frequency domain approach was able to model the roll response mode without the interference of the Dutch roll and spiral modes.

A flight envelope with points from all extremities was chosen in order to test the roll response mode for many different flight cases.

As future work, a higher number of flight tests from available spaces in the flight envelope maybe conducted to increase the database and improve the accuracy of the results.

The validation results obtained from the frequency domain method were good according to the FAA criteria, therefore the model used proved to be a suitable one to model the roll response of an aircraft.

The identified coefficients produced trends with angle of attack and Mach number that were effectively explained in the previous section. It is important to be able to interpret these patterns in order to validate the results obtained.

Finally, both methods satisfied the objectives successfully. These two methods were a good mode of comparison of the results obtained.

Other identification methods for the engine or aircraft are described in $[8,9,10$, $11,12,13,14,15,16,17,18,19,20,21$, 22].

\section{Acknowledgments}

The authors would like to thank to the NSERC for the funding received for this research. Thanks are dues to the CAE Inc. team led by $\mathrm{Mr}$ Ken Dustin for their support related to the Aircraft Research Flight Simulator, as well as to Mrs Odette Lacasse and Mr Oscar Carranza for their support and motivation.

\section{References}

1) Hamel, C., Sassi, A., Botez, R. M. and Dartigues, C., Cessna Citation $\mathrm{X}$ Aircraft Global Model Identification from Flight Tests, SAE International Journal of Aerospace, Vol. 6(1), (2013), 106.

2) Hamel, C., Botez, R. M. and Ruby, M., Cessna Citation X Airplane Grey-Box Model Identification without Preliminary Data, Proceedings of the SAE 2014 Aerospace Systems and Technology Conference, Cincinnati, United States, September 24-26, (2014).

3) Boughari, Y., Botez, R. M., Ghazi, G. and Theel, F., Evolutionary Algorithms for Robust Cessna Citation X Flight Control, SAE 2014 Aerospace Systems and Technology Conference, Cincinnati, United States, September 24-26, (2014).

4) Boughari, Y., Botez, R. M., Theel, F. and Ghazi, G., Optimal Flight Control on Cessna X Aircraft using Differential Evolution. International Association of Science and Technology for Development IASTED Modelling, Identification and Control (MIC 2014), Innsbruck, Austria, February 17-19, (2014).

5) Ghazi, G. and Botez, R. M., New Robust Control Analysis Methodology for Lynx Helicopter and Cessna Citation X Aircraft Using Guardian Maps, Genetic Algorithms and LQRTheories Combinations, American Helicopter Society 70th Annual Forum \& Technology Display, Montreal, Canada, May 20-25, (2014).

6) Rodriguez Fajardo, L. and Botez, R. M., Generic new modelling technique for turbofan engines thrust, The AIAA Journal of Propulsion and Power, Vol. 29(6), pp. 1492-1495.

7) Rodriguez Fajardo, L., Botez, R. M., Civil turbofan engines semi-empirical thrust generic model, IECON 2012 Conference, Montréal, Québec, Canada, 25-28 October, (2012).

8) De Jesus Mota, S.., Nadeau Beaulieu M. and Botez, R. M., Identification of a MIMO State Space 
Model of an F/A-18 Aircraft using a Subspace Method. The Aeronautical Journal, Vol. 112(1142), (2009), 183.

9) Kouba, G., Botez, R. M. and Boëly, N., Fuzzy Logic Method used in the F/A-18 Aircraft Model Identification, Journal of Aircraft, Vol. 47(1), (2010), 117.

10) Boëly, N., Botez, R. M. and Kouba, G., Identification of a Nonlinear F/A-18 Model by use of Fuzzy Logic and Neural Network Methods. Proceedings of the Institution of Mechanical Engineering, Part G: Journal of Aerospace Engineering, Vol. 225, (2010), 559-574.

11) Boëly, N., Botez, R. M., New Approach for the Identification and Validation of a Nonlinear F/A-18 Model by use of Neural Networks, IEEE Transactions on Neural Networks, Vol. 21(11), (2010), 1759-1765.

12) Nadeau Beaulieu, M., Botez, R. M., Simulation and Prediction of the Helicopter Main Rotor, Tail Rotor and Engine Parameters by using the Subspace System Identification Method, Proceedings of the Institution of Mechanical Engineers Part G: Journal of Aerospace Engineering, Vol. 222(G6), (2008), 817-834.

13) Boëly, N., Botez, R. M., New Methodologies for the Identification and Validation of a Nonlinear F/A-18 Model by use of Neural Networks, Invited Papers Session: Aircraft Aeroservoelastic Control, Modeling, Simulation, and Optimization, AIAA Atmospheric Flight Mechanics Conference, Toronto, Ont., Canada, (2010), August 2-5.

14) De Jesus Mota, S., Botez, R. M., 2009, "New Identification Method based on Neural Network for Helicopters from Flight Test Data, AIAA Atmospheric Flight Mechanics Conference, Chicago, IL, USA, (2009), August 10-13.

15) Boëly, N., Botez, R., Kouba, G. and Brenner, M., Identification of a
Nonlinear Model between Control and Structural Deflections of an F/A-18 Aircraft, 47th AIAA Aerospace Sciences Meeting including The New Horizons Forum and Aerospace Exposition, Paper AIAA 2009-426, Orlando, Florida, USA, (2009), January 5-8.

16) Nadeau Beaulieu, M., Botez, R. M., Prediction of Main Rotor, Tail Rotor and Engine Parameters from Flight Tests, 49th AIAA/ASME/ASCE/AHS/ASC Structures, Structural Dynamics, and Materials Conference, Paper AIAA 20082181, Shaumburg, IL, USA, (2008), April 7-11.

17) Nadeau Beaulieu, M., De Jesus Mota, S. and Botez, R. M., Flight Model Identification of an F/A-18 from Flight Tests, 17th International Federation of Automatic Control IFAC Symposium on Automatic Control in Aerospace, Toulouse, France, (2007), June 25-29.

18) Jategaonkar, R. V., Flight vehicle system identification a time domain methodology. Reston, VA: American Institute of Aeronautics and Astronautics, (2006).

19) Klein, V., Aircraft system identification theory and practice. Reston, VA: American Institute of Aeronautics and Astronautics, (2006).

20) Tischler, M. B., Aircraft and rotorcraft system identification engineering methods with flight-test examples. Reston, VA: American Institute of Aeronautics and Astronautics, (2006).

21) Morelli E. A. and Klein, V., 2005, Application of system identification to aircraft at NASA Langley Research Center, Journal of Aircraft, Vol. 4(1), (2005), 12.

22) Jategaonkar, R. V., Fischenberg, D. and Gruenhagen, W. V., Aerodynamic modeling and system identification from flight data - Recent applications at DLR, Journal of Aircraft, Vol. 41(4), (2004). 